\title{
Neck Circumference
}

National Cancer Institute

\section{Source}

National Cancer Institute. Neck Circumference. NCI Thesaurus. Code C154891.

A circumferential measurement of the neck, just below the larynx. 